\title{
Optimization of Power Density of Axial Flux Permanent Magnet Brushless DC Motor for Electric Two-Wheeler
}

\author{
Amit Narayanbhai Patel \\ Department of Electrical Engineering, Institute of Technology, Nirma University, Ahmedabad, India
}

(Corresponding author's e-mail: amit.patel@nirmauni.ac.in)

Received: 8 February 2021, Revised: 8 May 2021, Accepted: 8 June 2021

\begin{abstract}
The main objective of this work is to optimize the power density of axial flux permanent magnet brushless dc (PMBLDC) motor based on genetic algorithm (GA) technique for performance improvement of electric 2-wheeler. Power density is one of the important performance parameter of motor as it significantly influences overall performance of electric 2-wheeler. Firstly, the rating of electric motor is determined according to the application requirements and vehicular dynamics. Axial flux PMBLDC motor of $250 \mathrm{~W}, 150 \mathrm{rpm}$ is designed to fit in to the rim of electric 2-wheeler based on assumption of various design variables. The salient contribution of this work is to suggest the best combination of design variables with the application of GA optimization technique for power density optimization. Comparative performance analysis is carried out between initially designed motor and optimized motor. Finally, 3 dimensional (3-D) finite element analysis (FEA) is performed to verify the results obtained from design optimization. Results obtained from FEA fairly validates the initial design and optimized design. It is analyzed that the power density of motor is enhanced by $42.85 \%$ with the proposed optimization technique. The proposed technique is implementable and complexity free. It may further be applied to the performance improvement of a non-linear design comprising different design variables.
\end{abstract}

Keywords: Axial flux PMBLDC motor, Power density, FEA, Optimization, Genetic algorithm

\section{Introduction}

Increased attention is paid globally on reducing carbon emission and improving air quality with the use of electric vehicles. Shortage of fossil fuel and its limited resources are additional driving factors of electric vehicles. Vehicle manufacturers are extensively involved in developing reliable and viable technology for electric vehicles. Major limitation of electric vehicles is less drive range and dimensional constraints. It is very essential to enhance drive range for wide acceptability of electric vehicles. Power density of electric motor is required to be enhanced to marginalize issues related to less drive range \& dimensional constraints and to improve overall performance of electric vehicle.

Permanent magnet (PM) motors have garnered interest in past decade due to high efficiency, small size, wide speed range and fast dynamic response [1]. There are 2 types of PM motors; radial flux motors and axial flux motors. Flux is radially established in radial flux PM motors, and current flows axially, while flux is established axially in axial flux PM motors, and current flows radially. Higher efficiency, flat shape, better copper utilization and compactness make axial flux PM motors superior to radial flux PM motors [2]. The axial flux PM motors are popularly used in many domestic and industrial applications where axial compactness is one of the important performance parameters $[3,4]$. According to the rotor \& stator numbers and positioning the axial flux PM motors are classified as single stator single rotor, single-stator double rotor, double stator single rotor, or multi stator multi rotor [5]. Axial flux PM motors' structure include surface mounted permanent magnets or interior permanent magnets. Single stator double rotor surface mounted topology of axial flux PM motor is considered in present study as it is the best suited motor in direct drive applications. Optimal design of electric motor is very important for vehicular applications hence it is the point of interest for many researchers. Xue et al. [6] presented optimization of in-wheel switched reluctance motor for electric vehicles. Yang et al. [7] discussed optimization of single sided axial flux PM machines considering 7 different variables. Optimization considering combinational function of efficiency and cost performed and validated with 2-D FEA [8]. Azari et al. [9] presented optimal design of radial flux brushless motor considering 10 design variables. 
Ilka et al. [10] presented optimization of radial flux permanent magnet de motor for minimum loss and maximum power density. Cheng et al. [11] presented mass and electromagnetic loss optimization of AFPMM for underwater propeller application considering various variables like outer radius, inner radius, stator core thickness, current density, coil height and PM thickness.

This paper focuses on the design optimization of double rotor sandwiched stator axial flux PMBLDC motor for electric 2-wheeler. Optimization of power density of electric motor is quit essential in electric 2-wheeler application hence power density is considered to be the objective function of optimization. Power density of motor is optimized for enhancement of overall performance of electric 2wheeler. The requirements of vehicle are: Laden weight of $150 \mathrm{~kg}$, maximum speed is $25 \mathrm{kmph}$ and acceleration requirement is $25 \mathrm{kmph}$ in $9 \mathrm{~s}$. The rating of axial flux PMBLDC motor is calculated for this application using vehicle dynamic equations [12]. Motor rating of $250 \mathrm{~W}, 150 \mathrm{rpm}$ calculated as per application requirements and vehicle dynamics. Sandwiched stator double rotor topology is the most compatible in electric 2-wheeler application. Double rotor sandwiched stator axial flux PM motor of 250 $\mathrm{W}$ and $150 \mathrm{rpm}$ is designed assuming various design variables. Computer Aided Design (CAD) algorithm is finalized. Design optimization is done using GA technique.

The main aim of this work is to suggest the best combination of design variables obtained using the technique of optimization the GA and the design of the motor based on optimized design variables. Section II presents methodology to determine motor rating as per the application requirement and vehicular dynamics. Design of axial flux PMBLDC motor is discussed in section III. Design optimization based on GA technique and simulation results are presented in section IV. FEA is performed for the validation of initial CAD based design and proposed optimized design based on GA and elucidated in section V. Section VI highlights the main contribution and conclude the entire discussion.

\section{Vehicle dynamics}

Dynamic opposing force is produced as a function of velocity due to the body and mass of the vehicle. Tractive force required for propelling the vehicle mainly consists frictional force, aero dynamic drag force and gradient resistance force [13]. Aerodynamic drag force depends on vehicle frontal area, air density, drag coefficient and velocity. The rolling force is attributed to the tire's contact with the road. The rolling force depends on the vehicle's rolling coefficient, vehicle mass and gradient. The coefficient of rolling depends on tire form, shape and road conditions. Gradient resistance force is experienced by vehicle while climbing upward. Motor rating is determined to provide sufficient torque to overcome road load consisting following opposing forces.

Tractive force, $F_{t}=F_{r}+F_{w}+F_{g}$

Rolling force, $F_{r}=m g f_{r}$

Aerodynamic drag, $F_{w}=\frac{1}{2} \rho_{a} A_{f} C_{d} v^{2}$

Gradient resistance force, $F_{g}=m g \sin \alpha$

Torque for vehicle propulsion can be calculated form below mentioned Eq. (5);

$T=F_{t} \times r$

where $F_{t}$ is tractive force and $r$ is radius of wheel.

Motor with this torque value is required to mount directly in wheel for direct drive applications. The amount of torque that the driving motor delivers is what plays a decisive role in determining the speed, acceleration and performance of an electric vehicle. Power required for vehicle propulsion can be calculated based on torque and angular speed $(\omega \mathrm{m})$. Energy need during acceleration of vehicle is also considered while peak power calculation of electric motor. Various vehicle parameters are shown in Table 1. 
Table 1 Vehicle parameters.

\begin{tabular}{ccc}
\hline Parameter & Symbol & Value \\
\hline Laden weight of vehicle & $m$ & $150 \mathrm{~kg}$ \\
Drive system & - & Direct drive \\
Speed & $v$ & $25 \mathrm{~km} / \mathrm{h}$ \\
Acceleration time & - & $09 \mathrm{~s}$ \\
Coefficient of friction & $f_{r}$ & 0.011 \\
Weight & $m$ & $150 \mathrm{~kg}$ \\
Density of air at $25^{\circ} \mathrm{C}$ & $\rho_{a}$ & $1.177 \mathrm{~kg} / \mathrm{m}^{3}$ \\
Grade angle & $\alpha$ & $0^{\circ}$ \\
Frontal area & $A_{f}$ & $0.9 \mathrm{~m}{ }^{2}$ \\
Aero dynamic drag co-efficient & $C_{d}$ & 0.7 \\
Gravitational co-efficient & $g$ & $9.81 \mathrm{~m} / \mathrm{s}^{2}$ \\
\hline
\end{tabular}

The driving cycle of electric vehicle of low speed in urban area application is shown in Figure 1. It includes typical characteristics like increase in speed, constant speed and braking. Power rating of electric motor is calculated for this driving cycle based on Eqs. (1) to (5). The calculated motor parameters based on above considerations and vehicle dynamics are shown in Table 2.

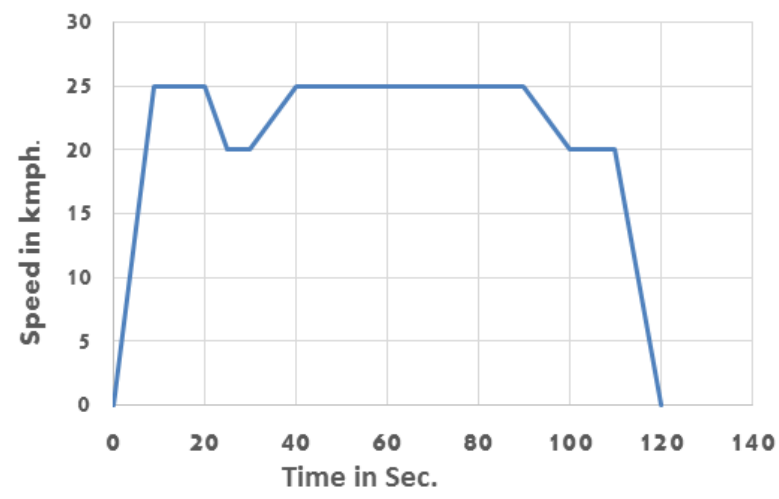

Figure 1 Drive cycle of vehicle.

Table 2 Motor rating.

\begin{tabular}{cc}
\hline Parameter & Value \\
\hline Rated power & $250 \mathrm{~W}$ \\
Voltage & $48 \mathrm{~V}$ \\
Rated torque & $15.91 \mathrm{Nm}$ \\
Maximum power & $803.44 \mathrm{~W}$ \\
Maximum torque & $58.32 \mathrm{Nm}$
\end{tabular}




\section{Computer aided design of axial flux PMBLDC}

Axial flux double rotor single stator PMBLDC motor is shown in Figure 2. Rotor is made of NdFeb type high energy permanent magnet and soft core material. Stator is made of ring type winding and M19 type core material. Calculation of main dimensions, stator design, rotor design and performance analysis are main steps of electrical machine design [14].

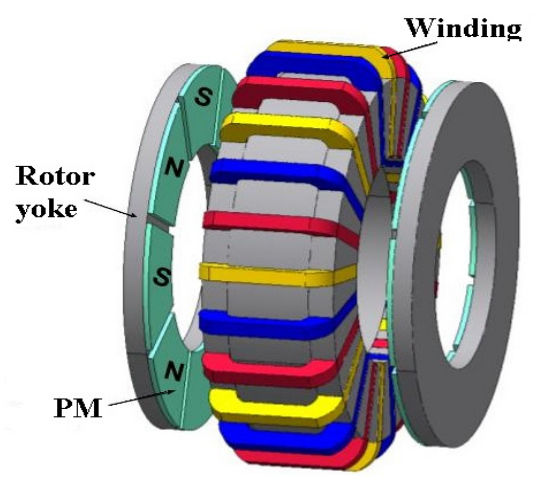

Figure 2 Axial flux PMBLDC motor.

Figure 3 depicts the block diagram of CAD program for axial flux surface mounted PMBLDC motor. Input data for $\mathrm{CAD}$ includes motor power rating, speed, operating voltage, initially assumed efficiency and material availability. Based on input data design and performance estimation is done. The flowchart contains 2 loops. If the difference between assumed air gap flux density and actual air gap flux density is more than acceptable error band then inner loop will change the length of magnet $\left(l_{p m}\right)$ and if the difference between calculated efficiency and assumed efficiency is not within acceptable error band then outer loop will modify initially assumed design variables. The volume of the materials applied that depend on the geometry of the motor has significant impacts on the cost of the motor [15].

Power density of axial flux PMBLDC motor can be expressed as under;

$$
P_{d e n}=\frac{P}{\pi / 4 D_{o}^{2} L}
$$

where $\mathrm{D}_{\mathrm{o}}=$ Outer diameter of motor and $\mathrm{L}$ is axial length.

The above-mentioned equation of power density is selected as subject function to be optimized.

Outer diameter of axial flux PMBLDC motor can be calculated form below mentioned equation;

$$
D_{o}=\sqrt{\frac{3 T}{\eta N_{c} N_{m} N_{s p p} K_{w} B_{g} I_{s}}}
$$

Axial length of motor can be calculated form below mentioned equation;

$$
L=L_{S c}+2 L_{S S}+2 L_{g}+2 L_{p m}+2 L_{r c}
$$

where $T=$ torque, $\eta=$ efficiency, $N_{c}=$ no. of coils excited at a time, $N_{m}=$ no. of poles, $N_{s p p}=$ no. of slots per pole per phase, $K_{w}=$ winding factor, $B_{g}=$ air gap flux density, $I_{s}=$ slot loading. $L_{s c}=$ length of stator core, $L_{s s}=$ length of slot, $L_{g}=$ length of air-gap, $L_{p m}=$ length of permanent magnet and $L_{r c}=$ length of rotor core. 


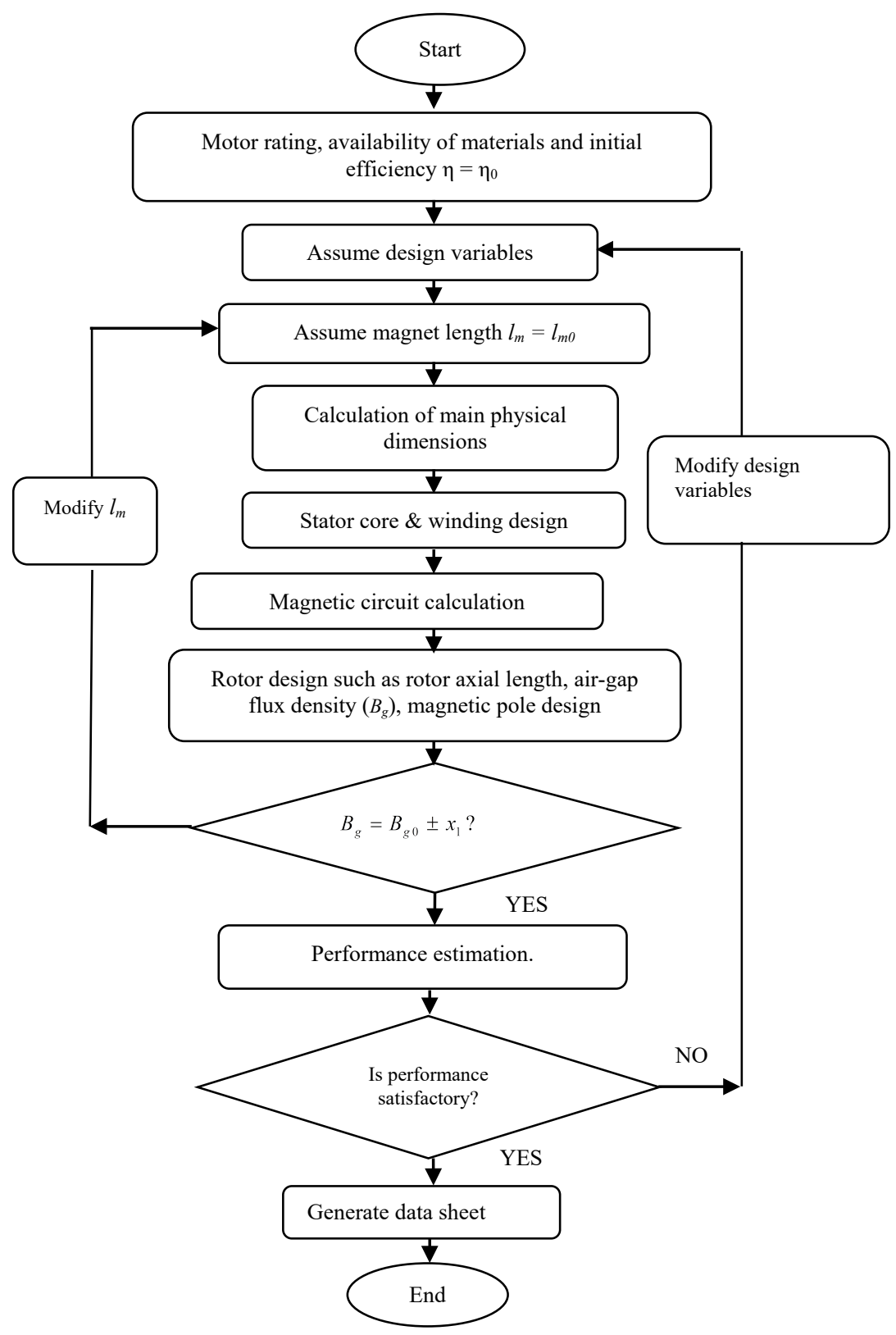

Figure 3 Block diagram of CAD.

Length of stator core depends on established magnetic flux and assumed flux density in stator core while length of stator slot depends on number of stator conductors, assumed current density, assumed conductor packing factor and slot aspect ratio. Length of air-gap is one of the important design variables as it influences the performance of axial flux PMBLDC motor significantly. Length of permanent magnet and length of rotor core can be determined form below mentioned equations.

$$
\begin{aligned}
& L_{p m}=\frac{B_{g} l_{g}}{0.2\left(\left(0.9 \times B_{r}\right)-B_{g}\right)} \\
& L_{r c}=\frac{B_{u} \pi D_{O}(1+\lambda)}{8 N_{m} B_{c r}}
\end{aligned}
$$

where $B_{r}=$ remanence, $B_{u}=$ attainable flux density on PM surface, $\lambda$ = diametric ratio, $B_{c r}=$ rotor core flux density. 


\section{Design optimization based on genetic algorithm}

GA is considered the most appropriate optimization technique for electrical motor design because it is nonlinear process involving many design variables having specified upper band and lower band [10]. Table 3 shows 5 influencing design variables with upper and lower band. Design variables influencing power density of motor are identified based on parametric analysis. The design variables usually affect each other and vary at the same time. Limits of design variables is governed by materials' availability, manufacturing process and performance requirement.

Table 3 Design variables and limits.

\begin{tabular}{cc}
\hline Variable & Limits \\
\hline $\mathrm{X}_{1}=\mathrm{B}_{\mathrm{g}}:$ Air gap flux density & $0.4 \mathrm{~T} \leq \mathrm{B}_{\mathrm{g}} \geq 0.9 \mathrm{~T}$ \\
$\mathrm{X}_{2}=$ Is: Slot loading & $100 \mathrm{~A} \leq \mathrm{I}_{\mathrm{s}} \geq 400 \mathrm{~A}$ \\
$\mathrm{X}_{3}: \mathrm{K}_{\mathrm{r}}$ : Diametric ratio & $1.3 \leq \mathrm{K}_{\mathrm{r}} \geq 2.5$ \\
$\mathrm{X}_{4}=\delta$ : Current density & $4 \mathrm{~A} / \mathrm{mm}^{2} \leq \delta \geq 10 \mathrm{~A} / \mathrm{mm}^{2}$ \\
$\mathrm{X}_{5}=1_{\mathrm{g}}:$ Air gap length & $0.25 \mathrm{~mm} \leq 1_{\mathrm{g}} \geq 1.0 \mathrm{~mm}$
\end{tabular}

GA starts with number of design variables used for optimal design, the function which is to be optimized (fitness function), number of populations \& generations and upper as well as lower limits of design variables. Figure 4 illustrates block diagram of GA based optimization technique. To optimize motor design there are mainly 4 operators: (i) Generate population (ii) Selection (iii) Crossover (iv) Mutation. Here motor power density is taken as a fitness function.

The population is produced arbitrarily from different design variables within the given ranges.

Population is a set of different chromosomes which have different genes for objective function and different values. Chromosome is randomly produced and consideration is given to only 1 chromosome from entire population.

In the selection procedure the entire population is initially sorted by fitness value. The selection process retains chromosome with high power density and discards chromosome with low power density.

The crossover process ensures that diversity is preserved in the entire genesis cycle. The mating pool has selected population based on its fitness. Genes of the 2 same chromosomes are randomly combined, creating 2 entirely new and distinct chromosomes.

The mechanism of mutation causes sudden and unintended changes in the initial chromosomes. The mutation maintains diversity and affected by either increasing or decreasing the original genes randomly. 


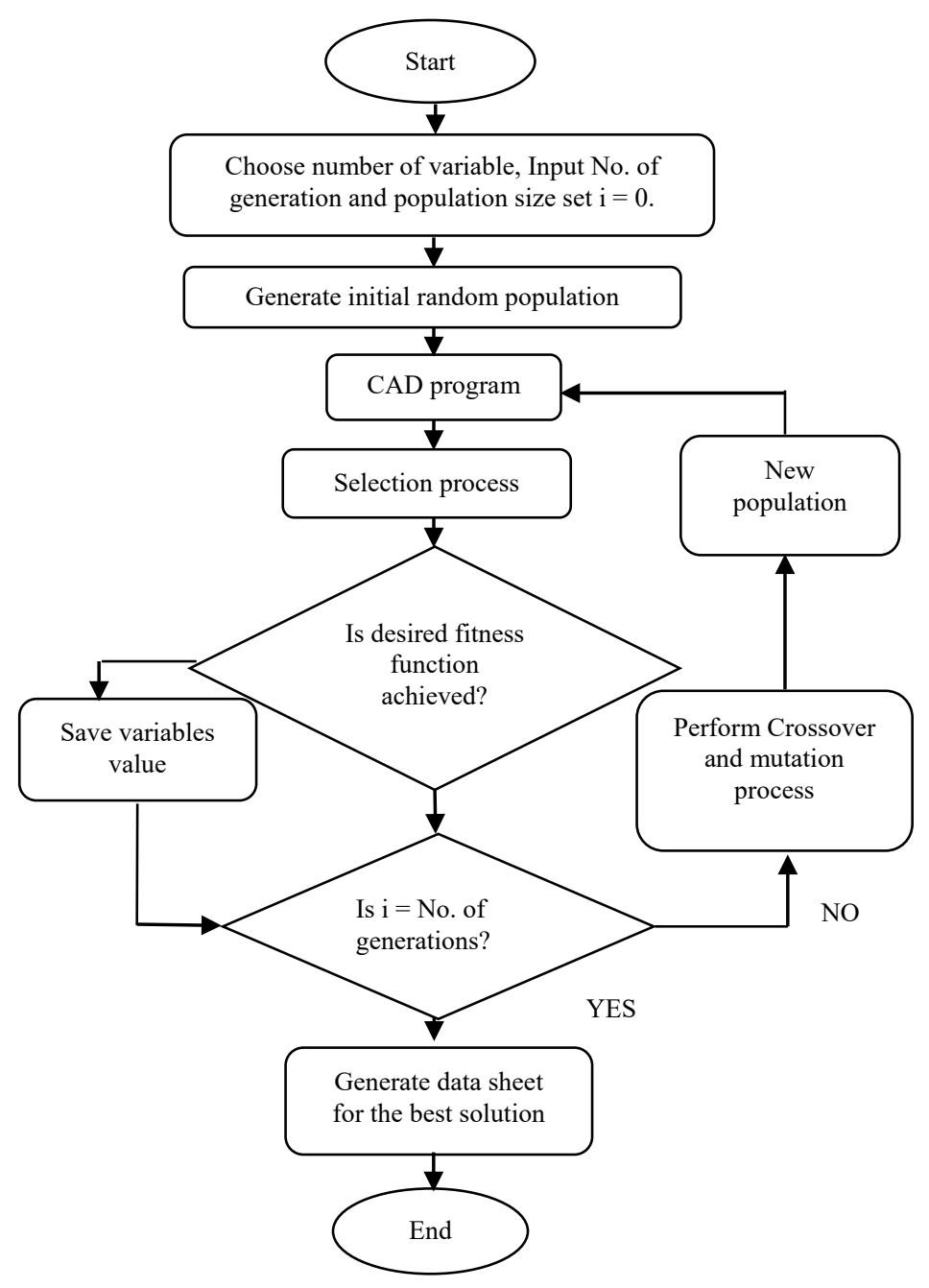

Figure 4 Block diagram of GA based optimization.

\section{Details of simulation}

The nonlinear nature of the GA makes it the most suitable for motor design optimization. Application of rare earth magnets allow air gap flux density between 0.4 to $0.9 \mathrm{~T}$. Current density between $4-10 \mathrm{~mm}^{2}$, air gap length between 0.25 to $1.0 \mathrm{~mm}$ and slot loading between 100 to $400 \mathrm{~A}$ are recommended for permanent magnet motor [9]. Table 4 illustrates each chromosome's $1 \times 5$ array for proposed optimization.

Table 4 Chromosome representation.

\begin{tabular}{|l|l|l|l|l|}
\hline $\mathrm{B}_{\mathrm{g}}$ & $\mathrm{K}_{\mathrm{r}}$ & $\delta$ & $\mathrm{I}_{\mathrm{s}}$ & $\mathrm{l}_{\mathrm{g}}$ \\
\hline
\end{tabular}

Power density is optimized using GA technique and effect of number of design variables on power density is shown in Table 5. It is observed that the fitness function i.e. power density is improved as the number of design variables are increased as illustrated in Table 5. 
Table 5 Effect of number of variables on optimal power density.

\begin{tabular}{cc}
\hline Variables & Power Density $\left(\mathbf{W} / \mathbf{m}^{3}\right)$ \\
\hline $\mathrm{B}_{\mathrm{g}}, \mathrm{K}_{\mathrm{r}}$ & $1.08 \times 10^{\wedge}$ \\
$\mathrm{B}_{\mathrm{g}}, \mathrm{K}_{\mathrm{r}}, \delta$ & $1.14 \times 10^{\wedge}$ \\
$\mathrm{B}_{\mathrm{g}}, \mathrm{K}_{\mathrm{r}}, \delta, \mathrm{I}_{\mathrm{s}}$ & $1.25 \times 10^{\wedge 5}$ \\
$\mathrm{~B}_{\mathrm{g}}, \mathrm{K}_{\mathrm{r}}, \delta, \mathrm{I}_{\mathrm{s}}, \mathrm{I}_{\mathrm{g}}$ & $1.50 \times 10^{\wedge 5}$ \\
\hline
\end{tabular}

Note that in the present study the population size selected was 100 with cross over probability as 75 and $1 \%$ mutation rate. The simulations were always carried out for 500 generations, however in few cases it is observed that the optimized result is achieved within 250 generations as shown in Figure 5. The execution time for the simulation was found to be $19.84 \mathrm{~s}$ for 500 generations. The simulations were carried out on Intel CPU core 3, I3-4150@3.50 GHz with 4 G RAM. Figure 5 illustrates that as number of generations are increased the fitness function (power density) is improved. Optimum power density of $1.50 \times 10^{\wedge 5} \mathrm{~W} / \mathrm{m}^{3}$ converged after 248 generations.

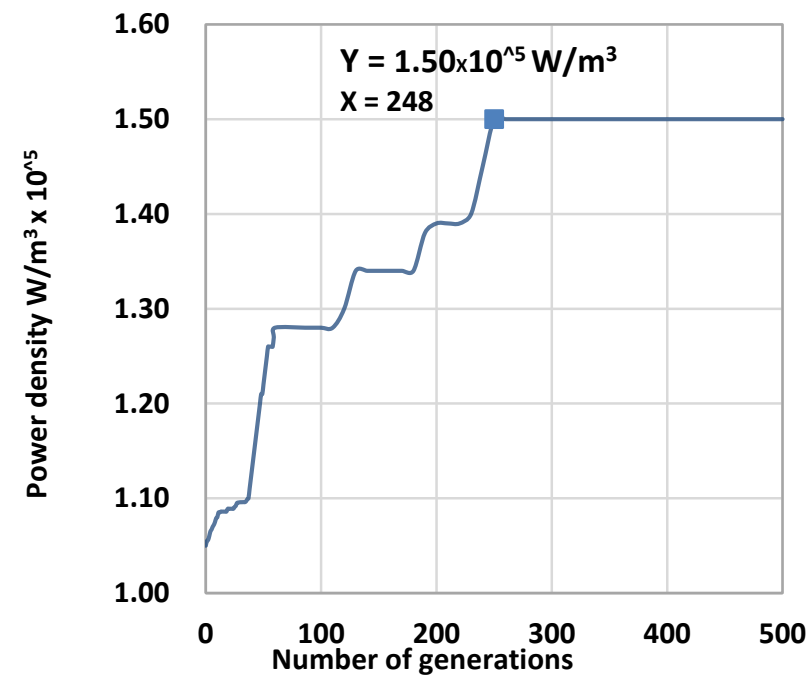

Figure 5 Variation of fitness function with number of generations.

Relative performance of initially CAD based designed motor and GA based unconstraint \& constraint design by taking CAD based design as a basis is illustrated in Figure 6. Design constraint represents limitation imposed of machine design. Owing to the space, manufacturability and economic considerations like constraints restrict the range of design variables. The axial length of motor is considered as dimensional constraint in constraint based optimization in this work. Initial power density of $1.05 \times 10^{\wedge} \mathrm{W} / \mathrm{m}^{3}$ obtained with CAD based design. It is observed that GA based unconstraint design with 5 variables gives the highest power density of $1.50 \times 10^{\wedge 5} \mathrm{~W} / \mathrm{m}^{3}$ with penalty of slight reduction in efficiency. 


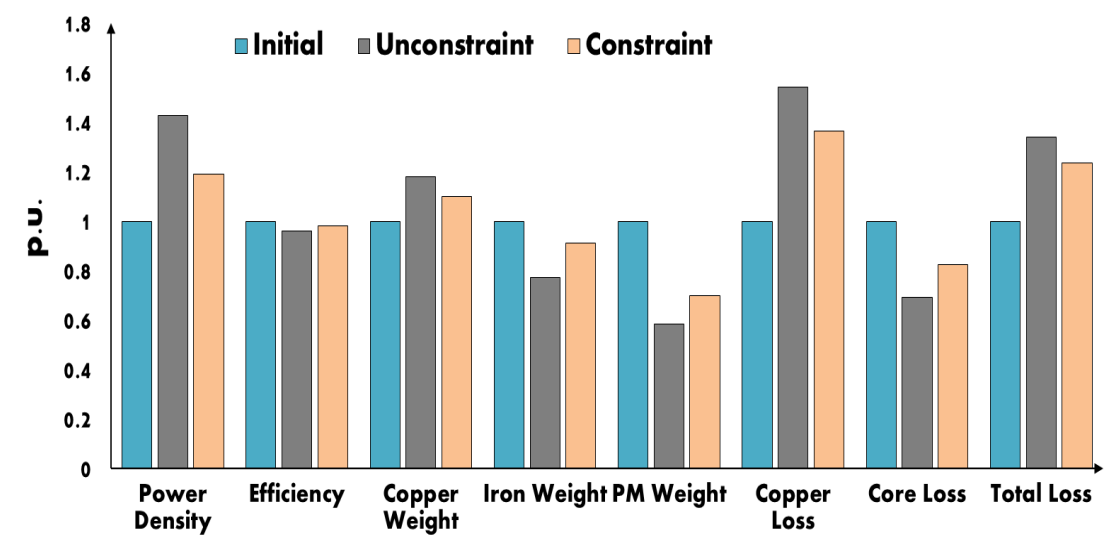

Figure 6 Relative performance of CAD and GA based optimized design.

CAD based design is carried out assuming slot loading $140 \mathrm{~A}$, air gap flux density $0.75 \mathrm{~T}$, magnet spacer width $7 \mathrm{~mm}$, air gap length $0.5 \mathrm{~mm}$, ratio of outer diameter to inner diameter 1.75 . Table 6 illustrates that the power density is improved with GA based optimized design in comparison to initial CAD based design.

Table 6 Comparison of initial and optimized design.

\begin{tabular}{lccc}
\hline \multicolumn{1}{c}{ Parameters } & Initial design & \multicolumn{2}{c}{ Optimized design } \\
\cline { 3 - 4 } & $1.05 \times 10^{\wedge 5}$ & $1.50 \times 10^{\wedge 5}$ Constraint \\
\hline Power density $\left(\mathrm{W} / \mathrm{m}^{3}\right)$ & 182 & 177 & $1.25 \times 10^{\wedge 5}$ \\
Outer diameter $(\mathrm{mm})$ & 104 & 95.2 & 184 \\
Inner diameter $(\mathrm{mm})$ & 26 & 34 & 97 \\
No. of turns/slot & 71.2 & 68.4 & 30 \\
Axial length $(\mathrm{mm})$ & 88.15 & 84.75 & 71.5 \\
Efficiency $(\%)$ & & & 85.75 \\
\hline
\end{tabular}

\section{Finite element analysis}

3-D FEA is carried out to validate initially CAD based design and GA based constraint design. FE model is prepared based on data obtained from initial design and optimized design with GA technique. Densed auto mesh has been created with $4 \mathrm{~mm}$ size tetrahedral elements. Magnetization pattern of permanent magnets was fixed according to the operating principle of motor. Flux travels circumferentially along stator core and crosses the air-gap. FEA is used to obtain torque profile, magnetic flux density spectrum and overall view of saturation level in various parts of the motor. Results obtained from the FEA validate initial design and GA based designs. Evaluation of magnetic flux density in various sections is essential to avoid saturation of core and teeth [16]. Saturation of core and/or teeth decreases the efficiency and degrades overall performance of motor. Flux density is assumed during sizing according to property of material and expected performance. Flux density distribution of initially designed motor and GA based optimized motor is obtained from FEA and shown in Figures $\mathbf{7}$ and $\mathbf{8}$, 
respectively. Comparative analysis of flux densities in various sections obtained from FEA and assumed during sizing is carried out and shown in Table 7. Flux densities obtained from FEA in various sections of magnetic circuit of initially designed motor and optimized motor are in line with the assumed flux densities respectively.

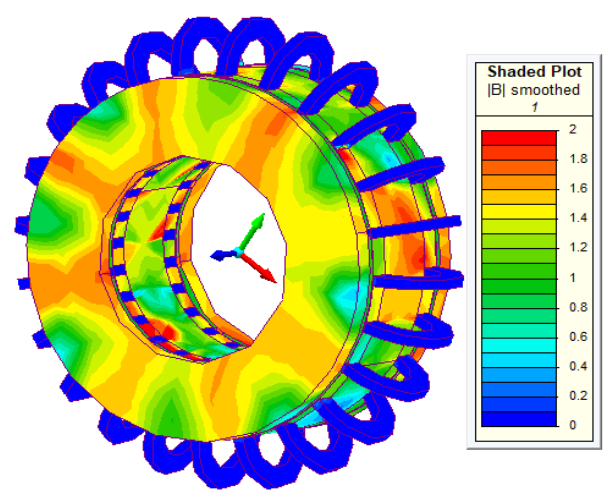

Figure 7 3-D flux density distribution of the CAD based AFPMBLDC motor.

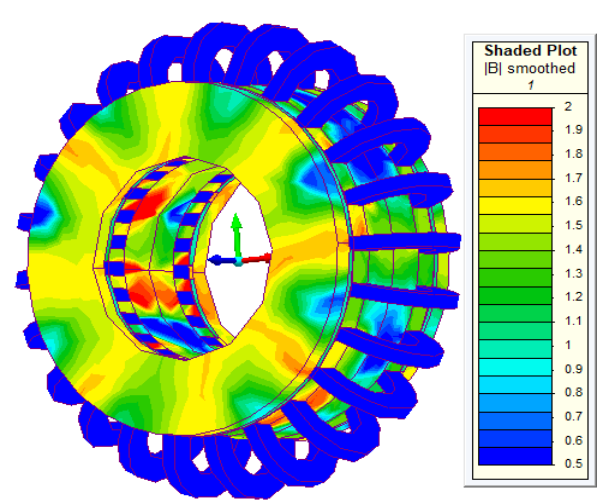

Figure 8 3-D flux density distribution of the GA based optimized AFPMBLDC motor.

3-D FEA is used to analyze the torque quality of initially designed motor and improved motor. To obtain the torque profiles of initially designed motor and improved motor, 3-D FEA calculations were performed for different rotor positions. Torque profile of CAD based initially designed motor and GA based optimized (constraint) motor are shown in Figure 9. Average torque obtained from FEA is fairly matching with CAD based designed motor and GA based optimized motor. Torque developed in FEA is marginally less by 1.19 and $3.01 \%$ with reference to CAD and GA based optimization respectively. This marginal difference is ascribed due to empirical formulas and nonlinear characteristic of magnetic materials. 


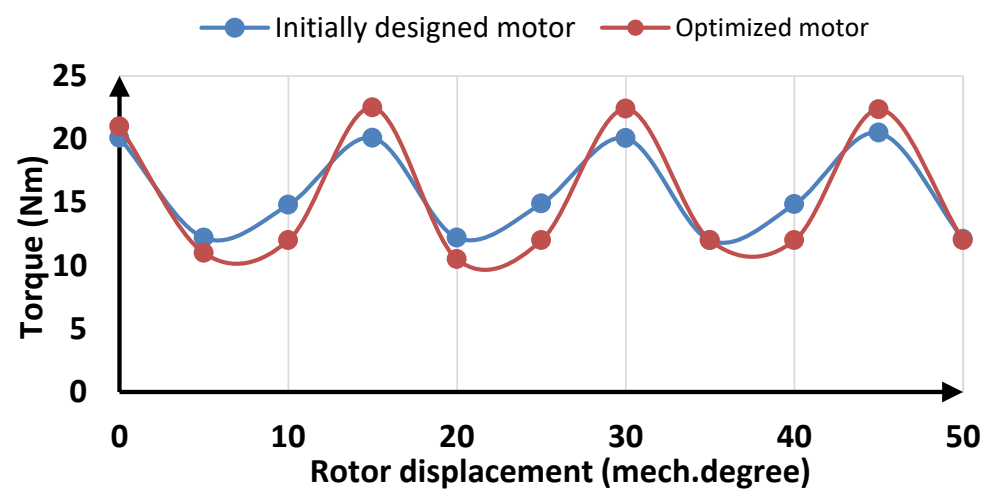

Figure 9 Torque profile of initially designed motor and optimized motor.

Table 7 Validation of designed axial flux PMBLDC motor.

\begin{tabular}{|c|c|c|c|c|c|}
\hline \multirow{2}{*}{\multicolumn{2}{|c|}{ Motor Parameters }} & \multicolumn{2}{|c|}{ Initial design } & \multicolumn{2}{|c|}{ Optimized design } \\
\hline & & CAD & $F E$ & $G A$ & $F E$ \\
\hline \multicolumn{2}{|c|}{ Average Torque (Nm) } & 15.91 & 15.80 & 15.91 & 15.43 \\
\hline \multirow{4}{*}{$\begin{array}{l}\text { Flux density } \\
\text { (T) }\end{array}$} & Air-gap & 0.75 & 0.76 & 0.78 & 79 \\
\hline & Stator core & 1.5 & 1.66 & 1.5 & 1.62 \\
\hline & Stator teeth & 1.7 & 1.75 & 1.7 & 1.78 \\
\hline & Rotor core & 1.5 & 1.60 & 1.5 & 1.56 \\
\hline \multicolumn{2}{|c|}{$\begin{array}{l}\text { Phase inductance } \\
(\mathrm{mH})\end{array}$} & 17.4 & 17.9 & 41.5 & 41.7 \\
\hline
\end{tabular}

\section{Conclusions}

Axial flux double rotor single stator motors are the most compatible with direct drive in-wheel applications due to its flat shape. Both unconstraint and constraint optimization based on GA improve the performance of axial flux PMBLDC motor. Optimization of design is carried out for initially designed $250 \mathrm{~W}, 150 \mathrm{rpm}$ motor for in-wheel electric 2-wheeler application. Power density of motor is enhanced by $42.85 \%$ with the unconstraint design optimization and $23.80 \%$ with the constraint design optimization. Increment in power density is very crucial performance enhancement in direct drive electric vehicle applications.

FEA is performed to authenticate the initial design and proposed GA based optimization. Results obtained from initial design and GA based constraint as well as unconstraint design are in close agreement with the results obtained from FEA. Effectiveness of GA based design optimization is established.

\section{References}

[1] V Sarac. Performance optimization of permanent magnet synchronous motor by cogging torque reduction. J. Electr. Eng. 2019; 70, 218-26.

[2] CC Chan. Axial field electrical machines-design and applications. IEEE Trans. Energ. Convers. 1987; EC-2, 294-300.

[3] RL Ficheux, F Caricchi, F Crescimbini and O Honorati. Axial flux permanent magnet motor for direct drive elevator system without machine room. IEEE Trans. Ind. Appl. 2001; 37, 1693-701.

[4] PR Upadhyay, KR Rajagopal and BP Singh. Computer aided design of an axial-field permanent magnet brushless dc motor for electrical vehicle. J. Appl. Phys. 2003; 93, 8689-91.

[5] M Aydin, S Huang and TA Lipo. Axial flux permanent magnet disc machines: A review. In: Proceedings of the Symposium on Power Electronics, Electrical Drives, Automation and Motion, Capri, Italy. 2004, p. 61-71. 
[6] XD Xue, KWE Cheng, TW Ng and NC Cheung. Multi-objective optimization design of in-wheel switched reluctance motors in electric vehicles. IEEE Trans. Ind. Electron. 2010; 57, 2980-7.

[7] X Yang, D Patterson and J Hudgins. Multi-objective optimization of a single sided axial flux permanent magnet machine. In: Proceedings of the International Conference on Electrical Machines and Systems, Busan, South Korea. 2013, p. 822-5.

[8] G Cvetkovski and L Petkovska. Multi-objective optimal design of permanent magnet synchronous motor. In: Proceedings of the IEEE International Power Electronics and Motion Control Conference, Varna, Bulgaria. 2016, p. 605-10.

[9] MN Azari, M Samami and SMA Pahnehkolaei. Optimal design of a brushless DC motor, by cuckoo optimization algorithm. Int. J. Eng. Trans. B Appl. 2017; 30, 668-77.

[10] R Ilka, AR Tilaki, H Asgharpour-Alamdari and R Baghipour. Design optimization of permanent magnet-brushless dc motor using elitist genetic algorithm with minimum loss and maximum power density. Int. J. Mechatron. Electr. Comput. Tech. 2014; 4, 1169-85.

[11] B Cheng, G Pan and Z Mao. Analytical calculation and optimization of the segmented-stator dualrotor axial flux permanent magnet motors. IEEE Trans. Magn. 2020; 56, 1-9.

[12] P Kumar and S Majhi. Introduction to hybrid and electrical vehicle - Module 2: Dynamics of electric and hybrid vehicles. NPTEL, Chennai, India, 2013, p. 1-28.

[13] A Nair and KR Rajagopal. Generic model of an electrical vehicle for dynamic simulation and performance prediction. In: Proceedings of the International Conference on Electrical Machines and Systems, Incheon, South Korea. 2010, p. 753-7.

[14] DC Hanselman. Brushless permanent magnet motor design. McGraw-Hill, New York, 1994.

[15] JR Handershot and TJE Miller. Design of brushless permanent magnet motors. Magna Physics, Oxford, UK, 1994.

[16] AH Levent, A Lordoglu and MG Aydeniz. Design and optimization of permanent magnet synchronous motor for electric vehicle applications. In: Proceedings of the $2^{\text {nd }}$ Global Power, Energy and Communication Conference, Izmir, Turkey. 2020, p. 148-51. 